\title{
Areal-averaged trace gas emission rates from long-range open-path measurements in stable boundary layer conditions
}

\author{
K. Schäfer ${ }^{1}$, R. H. Grant ${ }^{2}$, S. Emeis ${ }^{1}$, A. Raabe ${ }^{3}$, C. von der Heide ${ }^{4}$, and H. P. Schmid ${ }^{1}$ \\ ${ }^{1}$ Institute of Meteorology and Climate Research, Atmospheric Environmental Research (IMK-IFU), Karlsruhe Institute of \\ Technology (KIT), Kreuzeckbahnstraße 19, 82467 Garmisch-Partenkirchen, Germany \\ ${ }^{2}$ Department of Agronomy, Purdue University, 915 West State St., West Lafayette, IN 47907-2054, USA \\ ${ }^{3}$ Institute for Meteorology, University of Leipzig, Stephanstraße 3, 04103 Leipzig, Germany \\ ${ }^{4}$ Institute of Soil Science, Leibniz University Hannover, Herrenhäuserstraße 2, 30419 Hannover, Germany
}

Correspondence to: K. Schäfer (klaus.schaefer@imk.fzk.de)

Received: 13 November 2011 - Published in Atmos. Meas. Tech. Discuss.: 13 February 2012

Revised: 8 May 2012 - Accepted: 8 June 2012 - Published: 10 July 2012

\begin{abstract}
Measurements of land-surface emission rates of greenhouse and other gases at large spatial scales $\left(10000 \mathrm{~m}^{2}\right)$ are needed to assess the spatial distribution of emissions. This can be readily done using spatial-integrating micrometeorological methods like flux-gradient methods which were evaluated for determining land-surface emission rates of trace gases under stable boundary layers. Non-intrusive path-integrating measurements are utilized. Successful application of a flux-gradient method requires confidence in the gradients of trace gas concentration and wind, and in the applicability of boundary-layer turbulence theory; consequently the procedures to qualify measurements that can be used to determine the flux is critical. While there is relatively high confidence in flux measurements made under unstable atmospheres with mean winds greater than $1 \mathrm{~m} \mathrm{~s}^{-1}$, there is greater uncertainty in flux measurements made under free convective or stable conditions. The study of $\mathrm{N}_{2} \mathrm{O}$ emissions of flat grassland and $\mathrm{NH}_{3}$ emissions from a cattle lagoon involves quality-assured determinations of fluxes under low wind, stable or night-time atmospheric conditions when the continuous "steady-state" turbulence of the surface boundary layer breaks down and the layer has intermittent turbulence. Results indicate that following the Monin-Obukhov similarity theory (MOST) flux-gradient methods that assume a loglinear profile of the wind speed and concentration gradient incorrectly determine vertical profiles and thus flux in the stable boundary layer. An alternative approach is considered on the basis of turbulent diffusivity, i.e. the measured friction velocity as well as height gradients of horizontal wind speeds
\end{abstract}

and concentrations without MOST correction for stability. It is shown that this is the most accurate of the flux-gradient methods under stable conditions.

\section{Introduction}

The determination of trace gas and especially greenhouse gas (GHG) emission rates from open land is important to understand our climate and current and future changes in climate (Forster et al., 2007). There is high spatial variability of GHG fluxes from soils of the same type and under identical management (Turner et al., 2008). A better knowledge of the temporal and spatial variations of the trace gas fluxes requires an up-scaling of sources and sinks measurements near the surface (Denman et al., 2007). Up to now, a large amount of trace gas emission measurements has been done by timedependent accumulation of gasses in small (less than $1 \mathrm{~m}^{2}$ ) but variously-sized chambers (see e.g. Butterbach-Bahl et al., 2004). A possible larger-scale measurement technique of this sort is the time-dependent accumulation of trace gases in a measuring tunnel with open-path optical methods like FTIR (Fourier Transform InfraRed spectrometry), DOAS (Differential Optical Absorption Spectroscopy) or TDLAS (Tuneable Diode Laser Absorption Spectroscopy) along the longitudinal tunnel axis, which yields path-integrated concentration (PIC) values (see e.g. Galle et al., 1994; Schäfer et al., 2012). Measurements of fluxes at larger spatial scales 
$\left(10000 \mathrm{~m}^{2}\right)$ require the application of micro-meteorological methods (Smith et al., 1994).

Non-intrusive measurement methods like open-path optical techniques are well suited to study the uptake of trace gases by soils (Chapuis-Lardy et al., 2007) because they avoid any influences upon the soil emission processes by wind, temperature, humidity and radiation or heat fluxes. Further, measurements in the visible and infrared spectral range are only influenced by fog but not by rain so that almost continuous operation is possible. Ideally, path-integrated wind and turbulence measurements with identical control volumes to the concentration measurements should be used for flux determinations. Such path-integrated measures have been developed using laser-scintillometers (Nakaya et al., 2007) and acoustic travel-time tomography (Barth et al., 2007). Unfortunately, these measurement techniques possess wind speed detection limits of about $0.2 \mathrm{~m} \mathrm{~s}^{-1}$, and thus are not sensitive enough to describe the turbulence during stable and very stable conditions (Andreas, 2000). Furthermore, some of these methods depend on the validity of MoninObukhov similarity theory (MOST) which generally fails under stable conditions.

Finally, the conversion of spatially-representative concentrations and meteorological parameters to area fluxes requires knowledge of the area influencing the concentration measurement or source area of the sensor. The turbulent diffusion of gases and particles depends in part on the flow and turbulence conditions (Foken, 2008; Denmead, 2008). A "footprint function" is often used for micro-meteorological emission or flux measurement methods to relate the spatial distribution of surface sources (or sinks) to the measured flux (Schmid, 1994). However, existing footprint analyses are based on MOST, i.e. they cannot be applied during stable and very stable boundary layer conditions common at night. During stable (commonly nocturnal) conditions, the nearsurface wind will cease even in cases with moderate winds in the free atmosphere because the stabilization of the surface layer decouples the surface layer from the free atmosphere above, and different processes interact non-linearly on several temporal and spatial scales (Fernando and Weil, 2010). Although no continuous turbulence production takes place and "steady-state" conditions cease, the layer can have intermittent and wave-like turbulent structures. While intermittent turbulence may be representable in path-integrated measurements and contribute to the flux under stable conditions, the non-transporting wave structure must be removed from the computation of fluxes,

It is the objective of this paper to present a method for areal-averaged emission rates made during periods of low wind speed and stable boundary layers using open-path gas measurement techniques. We propose an alternative fluxgradient approach under these conditions that is not dependent on MOST. This approach was evaluated for two different open-path gas flux measurement campaigns and shown to give results comparable to averaged chamber measurements and an integrated horizontal flux (IHF) method. The qualityassurance procedures presented attempt to include the intermittent turbulence and exclude the wave structures from flux determinations. Note that the methods evaluated here substitute point measurements in the usual flux-gradient methods by integrated open-path concentration measurements (Wichink Kruit et al., 2007, 2010; Luhar et al., 2009) in order to extend the spatial representativeness of flux measurements.

\section{Flux measurement methods}

The determination of gas fluxes from open land during stable atmospheric conditions was studied in two different cases. Several flux measurement methods are applied to show and discuss the differences and to propose a methodology to handle stable conditions. Three-dimensional (3-D) sonic anemometers are used to measure wind and turbulence. Two non-intrusive path-integrating measurement methods (FTIR and TDLAS) are utilized for flux calculation.

\subsection{Measurement campaigns}

Two experiments were conducted: one at Fuhrberg, Germany and one at Indiana, USA. The Fuhrberg experiment was performed in a Festuca rubra field of $20-40 \mathrm{~m}$ thick sand. $\mathrm{N}_{2} \mathrm{O}$ soil emission studies were performed at this flat grassland, which had last been tilled in July 2005, from 2006 until 2008 (Deurer et al., 2008). The Indiana experiment was conducted around an actively-used cattle lagoon (dairy waste lagoon) with a negligible rise to the lagoon berm. The lagoon was surrounded by flat land. $\mathrm{NH}_{3}$ emission measurements were made as part of the National Air Emissions Monitoring Study (NAEMS) at representative swine, dairy, egg layer, and broiler production facilities in the USA. The Indiana experiment involved only micro-meteorological flux measurement methods, while the Fuhrberg experiment included both chamber and micro-meteorological. All measurement data were averaged over 30-min intervals.

\subsubsection{Micro-meteorological $\mathrm{N}_{2} \mathrm{O}$ emissions of a flat grassland (Fuhrberg experiment)}

Gaseous emissions of $\mathrm{N}_{2} \mathrm{O}$ were determined from wind and turbulence measurements made by 3-D sonic anemometers and gas concentration measurements using an openpath FTIR during two campaigns (15-17 October 2007 and 17-19 June 2008). The concentration differences of $\mathrm{N}_{2} \mathrm{O}, \mathrm{CO}_{2}, \mathrm{CH}_{4}$ and $\mathrm{H}_{2} \mathrm{O}$ over the field were measured by two bi-static open-path FTIR spectrometers (Griffith, 2002) K300 from Kayser-Threde (Haus et al., 1994): one at $2.70 \mathrm{~m}$ a.g.l. (above ground level), $z^{+}=2.70 \mathrm{~m}$, and one at $0.5 \mathrm{~m}$ a.g.1., $z^{-}=0.50 \mathrm{~m}$ (Fig. 1). Both FTIR paths were $98 \mathrm{~m}$ in length and parallel to each other. The lower measurement 
Table 1. Data which have been filtered at all heights for the quality-assured determinations of fluxes under low wind, stable or night-time atmospheric conditions and acceptable ranges for the various parameters.

\begin{tabular}{|c|c|c|c|}
\hline \multirow[t]{2}{*}{ Parameter } & \multirow[t]{2}{*}{ Phenomenon evaluated } & \multicolumn{2}{|c|}{ Acceptable range/criterion } \\
\hline & & Fuhrberg & Indiana \\
\hline 30-min mean wind & $\begin{array}{l}\text { directional shear between the heights } \\
\text { wind direction variation } \\
\text { wind speed limit }\end{array}$ & \multicolumn{2}{|c|}{$\begin{array}{l}\text { within } 45^{\circ} \text { of the perpendicular to a measurement plane } \\
\qquad>0.1 \mathrm{~m} \mathrm{~s}^{-1}\end{array}$} \\
\hline $\begin{array}{l}\text { perturbation of wind } \\
\text { components } u^{\prime}, v^{\prime}, w^{\prime}\end{array}$ & spikes & \multicolumn{2}{|c|}{$\begin{array}{c}>5 \text { standard deviations above the mean over } 5 \mathrm{~min} \text {, } \\
\quad>80 \% \text { of measurements had to be valid }\end{array}$} \\
\hline $\begin{array}{l}\text { perturbation of vertical } \\
\text { wind component } w^{\prime}\end{array}$ & intermittency and waves & \multicolumn{2}{|c|}{ visual inspection of 30 -min means } \\
\hline $\begin{array}{l}\text { vertical turbulence } \\
\left(\text { mean } w^{\prime 2}\right) \sigma_{\mathrm{w}}^{2}\end{array}$ & analysis of spectral distribution & \multicolumn{2}{|c|}{ similarity at both heights } \\
\hline calculated $\varsigma$ & analysis of spectral distribution & \multicolumn{2}{|c|}{ continuity, consistency across heights } \\
\hline bulk Richardson number $R i_{\mathrm{B}}$ & $\begin{array}{l}\text { dominance of turbulent production } \\
\text { over destruction }\end{array}$ & - & $<0.2$ \\
\hline $\begin{array}{l}\text { concentration differences } \\
\text { across height }\end{array}$ & consistency & $\begin{array}{c}\text { difference }>0 \text { to statistical } \\
\text { errors (combined errors with } \\
0.90 \text { levels, t-statistics: factor } 1.44 \text { ) }\end{array}$ & consistency across heights \\
\hline
\end{tabular}

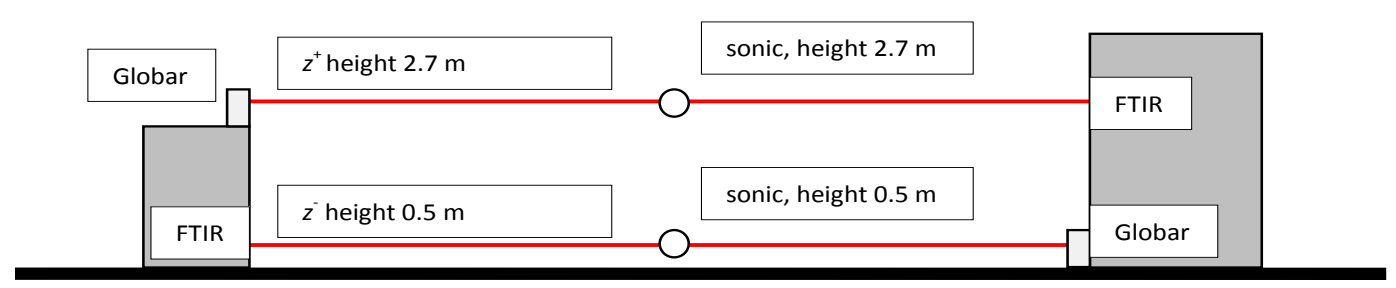

Fig. 1. Configuration of the Fuhrberg experiments with FTIR spectrometers and radiation sources (globars) showing the measurement paths and sonic anemometers. Chamber measurements were made in about $10 \mathrm{~m}$ distance to the one end of the FTIR paths. The measurement volume was oriented in north-south direction.

height was determined to be about 10 times the roughness length of the grassland.

The spectral resolution of the FTIR measurements was $0.2 \mathrm{~cm}^{-1}$, allowing the determination of interferences in the spectra and thus a high accuracy of the concentration measurements (Sussmann and Schäfer, 1997). The telescope of the spectrometers for the detection of the IR radiation of the radiation source had a diameter of $15 \mathrm{~cm}$ and a field of view of $3 \mathrm{mrad}$. The measurement time was about $5 \mathrm{~min}$. The measurements were running continuously, interrupted by short time periods for internal alignment procedures of the spectrometers ( 20 up to $60 \mathrm{~min}$ ) every 3 up to $6 \mathrm{~h}$. The minimum detection limit (MDL) of the K300 spectrometers at a $100 \mathrm{~m}$ open path was $5 \mathrm{ppb}\left(10 \mu \mathrm{g} \mathrm{m}^{-3}\right)$ for $\mathrm{N}_{2} \mathrm{O}$. The statistical concentration measurement error was less than $3 \%$ (Haus et al., 1994) and was calculated from the signal-tonoise-distance in the measured spectra for each measurement. This detection limit and measurement precision were appropriate to detect concentration differences of more than
$1 \%$. Griffith et al. (2002) and Esler et al. (2000), who used FTIR for micro-meteorological techniques as closed-path measurement method, found similar values. The temporal variations of the measured greenhouse gas concentrations at both heights followed the expected daily courses. The data quality filtering criteria are given in Table 1.

The 3-D sonic anemometers (USA-1) from Metek GmbH measured the wind and turbulence at the same heights as the FTIR open paths. Corresponding to the upper height the fetch or footprint, i.e. the required homogeneity in upwind direction, was about $270 \mathrm{~m}$. Considering the path lengths of about $100 \mathrm{~m}$, the investigated area was about $27000 \mathrm{~m}^{2}$.

A comparison of both open-path FTIR instruments was performed (22 and 23 November 2007 as well as 10 and 11 July 2008) following each flux-gradient measurement campaign. A $1 \mathrm{~h}$ inter-comparison of the mean winds measured by the two 3-D sonic anemometers was also performed, but this was completed in the field during the campaigns. The comparison-measured bias between FTIR spectrometers was 
used to correct the measured differences for each measurement campaign. No bias corrections were needed for the 3-D sonic anemometers.

\subsubsection{Chamber $\mathrm{N}_{2} \mathrm{O}$ emission of a flat grassland (Fuhrberg experiment)}

Gaseous emissions were determined from the time rate of change of $\mathrm{N}_{2} \mathrm{O}$ concentration in four closed chambers per time period measured. The chambers (area of $0.045 \mathrm{~m}^{2}$ each) were located on a plot of $1.5 \mathrm{~m}$ by $1.5 \mathrm{~m}$ in the vicinity of the micro-meteorological emission measurements (Sect. 2.1.1). Gas samples were collected in ambient air before closing of the chambers and every $20 \mathrm{~min}$ over $1 \mathrm{~h}$ after the closing. Measurements were performed the day following the open-path flux-gradient measurements at around 22:00 LT. Concentrations of $\mathrm{N}_{2} \mathrm{O}$ were analysed from the gas samples using a gas chromatograph (Fisons GC 8000, Milan, Italy) equipped with a split-injector, an electronic capture detector and a HP-PLOT Q column ( $30 \mathrm{~m}$ length $\times 0.32 \mathrm{~mm}$ ID; Agilent Technologies, Santa Clara, USA). The gas samples were analysed within 3 weeks after the collection (Weymann et al., 2009; von der Heide et al., 2009).

The $\mathrm{N}_{2} \mathrm{O}$ fluxes were determined and qualified for use by the linearity of the increases/decreases of the concentration measurement. As the $\mathrm{N}_{2} \mathrm{O}$ fluxes were very low, we chose a linearity criterion of the square of regression coefficient of 0.8 . If this coefficient was smaller than 0.8 , the flux rate of the chamber was set to zero. The non-steady-state diffusive flux estimator (NDFE) method of Livingston et al. (2006) was also used to determine the flux.

\subsubsection{Micro-meteorological $\mathrm{NH}_{3}$ emissions from a cattle lagoon (Indiana experiment)}

Gaseous emissions of $\mathrm{NH}_{3}$ were determined from wind measurements made by 3-D sonic anemometers (R. M. Young sonic 8100) and open-path gas concentration measurements using TDLAS (GasFinder 2.0, Boreal Laser, Inc). Measurements were made for a total of 321 days between September 2008 and August 2009.

Concentration gradients of $\mathrm{NH}_{3}$ were determined from scanning TDLAS measurements. The TDLAS units were set up at opposite corners of the $85 \mathrm{~m}$ by $116 \mathrm{~m}$ lagoon with $16 \mathrm{~m}$ towers placed at the other two corners of the lagoon (Fig. 2). Open-path $\mathrm{NH}_{3}$ measurements were made along each adjacent side of the lagoon at $0.9 \mathrm{~m}$ a.g.l. along paths extending about $1 / 3 \mathrm{rd}$ and $2 / 3 \mathrm{rds}$ and slightly more than the full distance down the side of the source and at two vertical angles to retro-reflectors between $85 \mathrm{~m}$ and $116 \mathrm{~m}$ away and at approximately $7.6 \mathrm{~m}$ a.g.l. and $15.2 \mathrm{~m}$ a.g.l. Thus, each side of the source has three near-surface paths and two elevated paths. The scanner sequentially aimed the TDLAS at one of the ten retro-reflectors on the two adjacent sides of the source such that a complete set of measurements occurred every $100 \mathrm{~s}$.

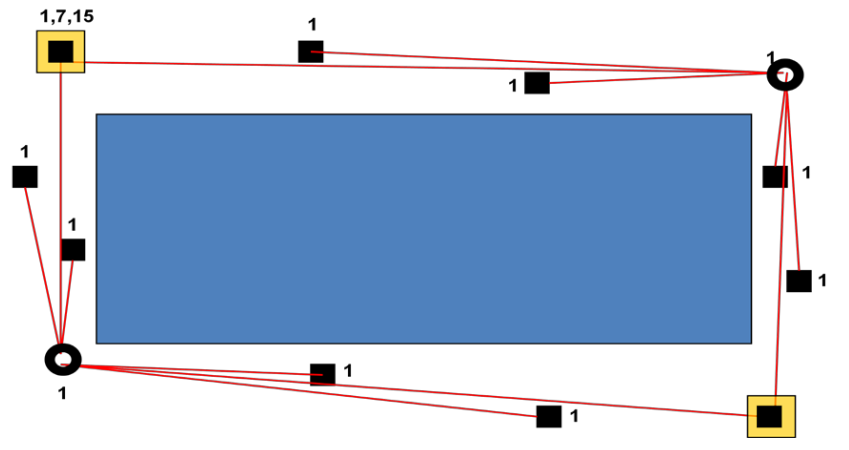

Fig. 2. Configuration of Indiana experiment. The scanning TDLAS (open circle), retro-reflectors (filled squares), towers (yellow squares) and open paths (solid lines) are shown with the height of the equipment indicated in meters.

Quality control (QC) checks for the TDLAS measurements included checks for path obstruction at every measurement, internal calibration checks at every 100 measurements, spectral feature check and single point calibration verification approximately every 21 days, and multi-point calibrations every six months. Based on twice the precision, the TDLAS units had a minimum detection limit of $2 \mathrm{ppm} \mathrm{m}$ or less. The TDLAS calibration was verified at $50 \mathrm{ppm}$ m using a $0.5 \mathrm{~m}$ calibration cell in an approximately $4 \mathrm{~m}$ path length. Spectral feature checks were made using a digital oscilloscope.

The 3-D sonic anemometers were mounted at $2.5 \mathrm{~m}\left(z^{-}\right)$, $4.4 \mathrm{~m}\left(z_{\mathrm{F}}\right)$, and $16.2 \mathrm{~m}\left(z^{+}\right)$height (Fig. 2). The wind speed and temperature gradient measurements were assured by frequent inter-comparisons of the three sensors in the field and three "reference" (unused except for calibration checks) anemometers. The comparison-measured bias between the temperature measurements of the sonic anemometers was used to correct the measured temperature gradients. No bias corrections were needed for the sonic anemometer wind measurements.

The TDLAS $\mathrm{NH}_{3}$ MDL was determined to be approximately $30 \mathrm{ppb}\left(13.9 \mathrm{\mu g} \mathrm{m}^{-3}\right)$ for the paths measured in the campaign. The statistical concentration measurement error across the measurement domain was measured at less than $5 \%$ based on calibration verifications.

Since the flow often has the lagoon upwind and the lagoon berm is both a roughness and height transition, we might expect convergence with turbulence regularly advected across the measurement planes.

The multiple downwind measurements in the plume in vertical planes perpendicular to the wind direction are also used for the integrated horizontal flux (IHF) method. These results are applied for comparison with the flux-gradient method. 


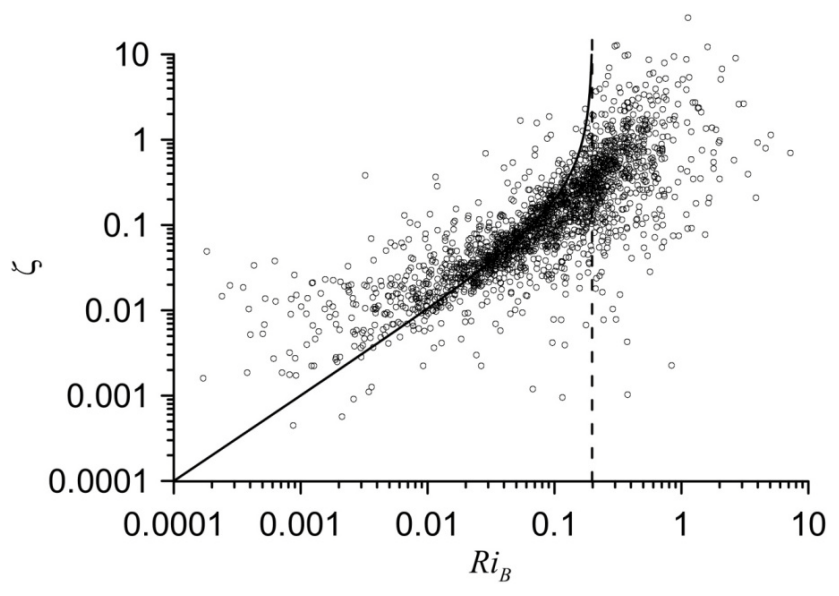

Fig. 3. Relationship between the two measures of overall stability stability $\varsigma$ from bulk Richardson number $R i_{\mathrm{B}}$ - during the Indiana experiment. The critical $R i_{\mathrm{B}}$ (dashed line) and $\mathrm{BDH}$ relationship (empirically-derived values from Businger et al., 1971, Dyer, 1974 and Hicks, 1976) below critical $R i_{\mathrm{B}}$ (solid line) are indicated.

\subsection{Sonic anemometers and quality assurance checks}

While 3-D sonic anemometer measurements were aligned to the natural wind coordinates for the Fuhrberg experiment conducted over a flat open field, they were not aligned in the Indiana experiment because the measurements were made in close proximity to a lagoon with a $1-3 \mathrm{~m}$ drop in elevation to the lagoon liquid surface. Turbulence statistics (variances and co-variances) were calculated for all heights except $0.5 \mathrm{~m}$ where it was expected that significant fractions of the turbulence would not be measureable by the sonic anemometer. The momentum flux and sensible heat flux were determined by the eddy-covariance method (Foken, 2008). The MoninObukov length $L$ was determined with $\theta_{\mathrm{v}}^{\prime}$ (perturbation in the virtual potential temperature), approximated by $\theta_{\mathrm{s}}^{\prime}$ (perturbation in sonic anemometer temperature), and $w^{\prime}$ (perturbation of the vertical wind speed). Since there is often a strong self-correlation between the turbulence quantities used in the calculation of $L$ and the gradient Richardson number is vulnerable to significant errors when the vertical wind profile is complex, the bulk Richardson number $R i_{\mathrm{B}}$ was used as an additional measure of overall stability (Mahrt, 2010).

The nature of the flow variability during each measurement period was evaluated. Tests used to evaluate the nature of the flow variability are summarized in Table 1 together with the acceptable ranges for the various parameters. The inter-comparisons during the Indiana experiment showed a mean difference between the field-used 3-D sonic anemometers and the reference anemometers of $0.03 \mathrm{~m} \mathrm{~s}^{-1}$ and up to $3 \mathrm{~K}$. Temperature bias between sonic anemometers was corrected prior to determination of $R i_{\mathrm{B}}$. During the Fuhrberg experiment typically differences between sensors were less

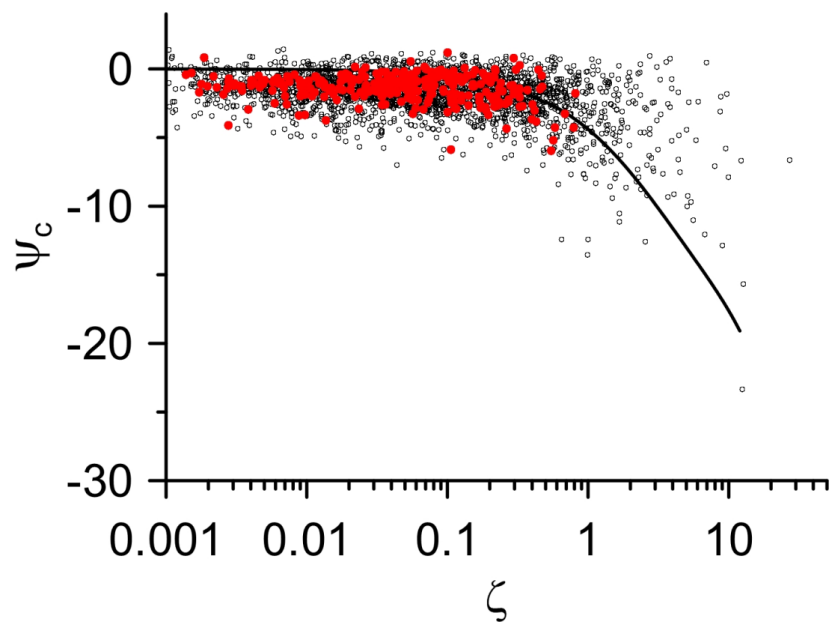

Fig. 4. Relationship for the trace gas stability correction function $\psi_{\mathrm{c}}$ between the dependence of integrated profile at $4.4 \mathrm{~m}\left(z_{\mathrm{F}}\right)$ based on measurements at $2.5 \mathrm{~m}\left(z^{-}\right)$and $16.2 \mathrm{~m}\left(z^{+}\right)$on stability $\varsigma$. The measured values (circles) and the nominal relationships according to Holtslag and de Bruin (1988) (solid line) are indicated. The remaining data after the quality assurance procedure stated in the text are red.

than $0.1 \mathrm{~m} \mathrm{~s}^{-1}$, zero flow check resulted in a flow of less than $\pm 0.05 \mathrm{~m} \mathrm{~s}^{-1}$.

Influences of non-turbulent motions and nonhomogeneous, unsteady flow were partially excluded from the data set by restrictions on the acceptable values of $R i_{\mathrm{B}}$ (Fig. 3). Distinct non-turbulent waves were evident in many of the most stable periods in the Indiana experiment: a $R i_{\mathrm{B}}$ of less than 0.2 corresponded to boundary layers with distinct (although sometimes weak) turbulence, consistent with theory (Luhar et al., 2009). The removal of all measurement periods where $R i_{\mathrm{B}}>0.2$ (Fig. 3) reduced the range of the stability $\varsigma=(z-d) / L$, where $d$ is the displacement height $(0.134 \mathrm{~m}$ for the Fuhrberg experiment and assumed zero for the Indiana experiment), to values less than 0.8 (Fig. 4) and the quality-assured dataset to 358 30-min measurement periods. Even with this exclusion, the deviation of the stability correction function $\psi_{\mathrm{c}}$ from the theoretical relationship with $\varsigma$ (Fig. 4) implies non-stationarity of the flow associated with waves, meandering flow and other coherent flow structures (Mahrt, 2007). Consequently, we also then expected differences between the diffusivity-based flux calculation and the MOST-theory based flux-gradient calculations since non-stationarity often results in more linear (not logarithmic) wind profiles (Mahrt, 2007).

\subsection{Micro-meteorological emissions methods}

Emissions were calculated (1) using the IHF method as well as (2) by a flux-gradient method using (2a) turbulent diffusivity as exchange coefficient (termed "similarity" method), (2b) using a MOST-parameterized stability correction to the 
MOST theorized wind and concentration profile (termed "parameterized" flux-gradient method), and (2c) that replaces the parameterizations for $c_{*}$ and $u_{*}$ with measurements (termed "measured $u_{*}$ " flux-gradient method).

\subsubsection{Open-path integrated horizontal flux method (IHF)}

Emissions of $\mathrm{NH}_{3}$ during the Indiana experiment were determined at 30-min intervals from wind profiles based on the three anemometers and concentration profiles based on the multiple TDLAS-measured PIC using the vertical radial plume mapping method (Hashmonay et al., 2001). This method utilizes the product of an interpolated mass concentration distribution and interpolated wind speed normal to the measurement plane and is therefore fundamentally an IHF method. Only measurement periods with valid measurements for all five PICs of a measurement plane for the entire 30-min period were included in the analysis. Comparisons between the IHF and the various flux-gradient methods discussed above were limited to periods of measurement when only one of the four planes had a measured flux. Because of the mismatch in sampling intervals between the sonic anemometer and the TDLAS, some of the flux measured by the IHF method would be a result of the covariance between horizontal wind perturbations and gas concentration perturbations (Denmead, 2008). We expect an overestimation of the flux using the IHF method of 5 to $20 \%$. Background concentrations of $\mathrm{NH}_{3}$ and the corresponding flux were assumed negligible.

\subsubsection{Open-path flux-gradient measurement methods}

Steady-state turbulence in the surface boundary layer and height-constant conditions were assumed for all fluxgradient methods. The "parameterized" flux-gradient method multiplies a parameterized friction velocity $u_{*}$ by the corresponding concentration scaling parameter $c_{*}$ according to MOST to get the flux (Foken, 2008). $u_{*}\left[\mathrm{~m} \mathrm{~s}^{-1}\right]$ was estimated according to Lege (1981) and the stability correction for trace gases was assumed to be identical to that for momentum (see e.g. Holtslag and de Bruin, 1988). The empirically-derived values are from Businger et al. (1971), Dyer (1974) and Hicks (1976) (termed BDH). The stability correction was estimated according to the suggested equations of Holtslag and de Bruin (1988). During the campaigns, $\psi_{\mathrm{c}}$ showed the expected relationship to $\varsigma$ with the exception that the values crossed the $\varsigma=0$ line below the expected value of $\psi_{\mathrm{c}}=0$ (Fig. 4). This suggests that either turbulence was advected into the profiles, variance in the motion of the boundary layer was associated with non-turbulent structures, and/or the wind profile was not log-normal. Although non-turbulent variance in motion associated with waves at high 5 also contribute to deviations from the theoretical relationship, periods with such motion were largely excluded from the analysis using procedures described below.

The "measured $u_{*}$ " flux-gradient method replaces the parameterizations for $c_{*}$ and $u_{*}$ with measurements: if the wind and concentration measurements are at the same heights, $\psi_{\mathrm{c}}$ can also be based on the measured values of $u_{*}$ by solving the $u_{*}$ equation for $\psi_{\mathrm{c}}$; and if the wind and concentration measurements are at different heights, $\psi_{\mathrm{c}}$ can be parameterized, while $u_{*}$ is determined directly from the sonic anemometer measurements.

The "similarity" method uses fewer assumptions than the "parameterized" or "measured $u_{*}$ " flux-gradient methods in that there is no assumed MOST correction for stability and no assumed neutral MOST logarithmic wind profile. The turbulent diffusivity $K_{\mathrm{c}}$ was calculated from the measured friction velocity $u_{*}$ (mean of the measured friction velocities in the heights $z^{+}$and $z^{-}$, see also Stull, 1997) and the measured height difference of the horizontal wind speeds $u\left[\mathrm{~m} \mathrm{~s}^{-1}\right]$ by

$K_{\mathrm{c}}=\frac{1}{S c} \cdot \frac{u_{*}\left(z_{\mathrm{F}}\right)^{2}}{\frac{u\left(z^{+}\right)-u\left(z^{-}\right)}{z^{+}-z^{-}}}$,

where $S c$ is the Schmidt number and $z_{\mathrm{F}}[\mathrm{m}]$ is the height of flux calculation. Lacking knowledge of the turbulent $S c$, we assume that the molecular value is a good first approximation of the turbulent $S c$. The molecular $S c$ is 1.079 for $\mathrm{N}_{2} \mathrm{O}$ and 0.63 for $\mathrm{NH}_{3}$ (Massman, 1998). The flux $F$ is then calculated with the vertical gradient of the concentration $c\left[\mu \mathrm{g} \mathrm{m}^{-3}\right]$ as:

$F\left(z_{\mathrm{F}}\right)=-K_{\mathrm{c}} \cdot \frac{\mathrm{d} c}{\mathrm{~d} z}=-K_{\mathrm{c}} \cdot \frac{c\left(z^{+}\right)-c\left(z^{-}\right)}{z^{+}-z^{-}}$.

\subsection{Application of open-path measurements for flux calculations}

The vertical $\mathrm{N}_{2} \mathrm{O}$ gradients were based on the quality-assured open-path FTIR measurements made ground-parallel. Concentration and wind measurements were made at $2.70 \mathrm{~m}$ and $0.5 \mathrm{~m}$ a.g.l.

The vertical $\mathrm{NH}_{3}$ gradients were derived from the slantpath measurements by defining three layers $(0-2.6 \mathrm{~m}, 2.6-$ $8 \mathrm{~m}$, and $8-15.2 \mathrm{~m}$ ) and assuming the gas is uniformly mixed within each layer. The concentrations of each layer were then determined by sequentially solving three equations with three unknowns; where the fractional length of the overall measurement path through each layer is known, the concentration through the entire layer is assumed uniform and the cumulative concentration of gas along the entire path is measured (see also Table 1). The wind gradient at $4.4 \mathrm{~m}$ height was determined from the wind measurements made at heights of $2.5 \mathrm{~m}$ and $16.2 \mathrm{~m}, 5$ determined from the $4.4 \mathrm{~m}$ sonic anemometer height, and the concentration gradient at $4.4 \mathrm{~m}$ height was determined from the gradient approximated from horizontal gradients of $\mathrm{NH}_{3}$ based on the TDLAS measurements. 


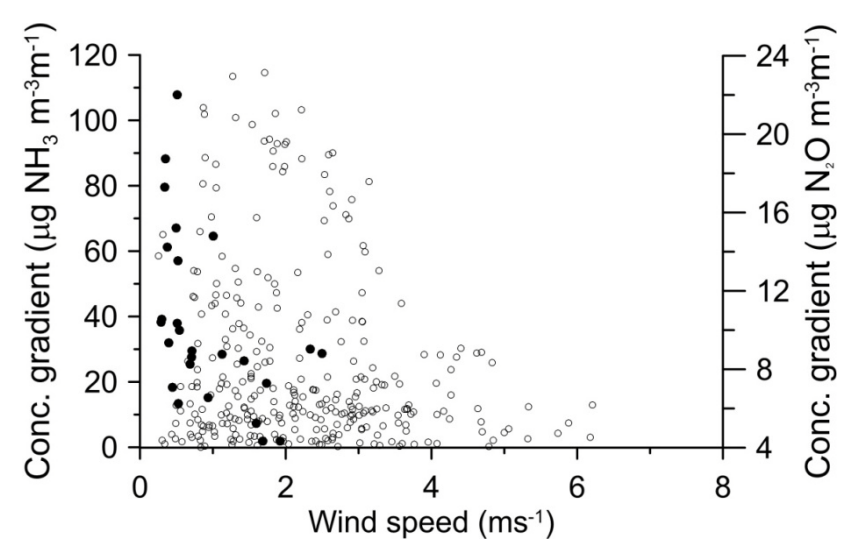

Fig. 5. Variation in concentration gradient relative to horizontal wind speed. Values in both the Indiana $\left(\mathrm{NH}_{3}\right.$, open circles) and Fuhrberg $\left(\mathrm{N}_{2} \mathrm{O}\right.$, closed circles) experiments are indicated.

The MDL of each flux-gradient methodology was evaluated assuming that the measurement errors are independent (Taylor, 1982). An analysis of the propagation of measurement errors for the "parameterized" flux-gradient method indicated a MDL of approximately $5 \%$ for the FTIRbased open-path measurement method and $12 \%$ for the both TDLAS-based open-path measurement method. The $K_{\mathrm{c}}$ MDL was approximately $0.01 \mathrm{~m}^{2} \mathrm{~s}^{-1}$ for the FTIR-based measurement method and $0.002 \mathrm{~m}^{2} \mathrm{~s}^{-1}$ for the TDLASbased measurement method. It is important to understand that these errors are only the propagation of measurement errors through the equations and not associated with the ability of a given method to describe the true flux given the variability in the environment.

\section{Results}

Results are shown for the turbulence measurements and the flux determination by the different methods during both campaigns.

\subsection{Atmospheric dynamics aspects}

The atmospheric conditions during the Fuhrberg experiment were similar to the stable boundary layer measurement periods of the Indiana experiment. In both experiments, the concentration gradient range in $\mathrm{NH}_{3}\left(0.6\right.$ to $\left.114.6 \mu \mathrm{g} \mathrm{m}^{-3} \mathrm{~m}^{-1}\right)$ and $\mathrm{N}_{2} \mathrm{O}$ (4.4 to $\left.22.0 \mu \mathrm{g} \mathrm{m}^{-3} \mathrm{~m}^{-1}\right)$ increased with decreasing wind speed (Fig. 5). There was no distinct relationship between the vertical $\mathrm{NH}_{3}$ and $\mathrm{N}_{2} \mathrm{O}$ concentration gradients and the vertical gradient in horizontal wind speed, however there was a tendency for greater concentration gradients corresponding to low horizontal wind speed gradients less than $0.2 \mathrm{~m} \mathrm{~s}^{-1} \mathrm{~m}^{-1}$. The maximum observed $\varsigma$ however differed somewhat: 0.81 in the Indiana experiment and 1.16 in the Fuhrberg experiment.
The turbulent conditions during the quality-assured 30min periods were also similar in both experiments (Fig. 6a), with the calculated $K_{\mathrm{c}}$ for both experiments decreasing with decreasing wind gradient and $u_{*}$ and decreasing with increasing $\varsigma$ for all stable measurement periods (normalized by $S c$ in Fig. $6 \mathrm{~b}$ and d). The wide range in possible $K_{\mathrm{c}}$ for a given wind speed gradient was a result of small gradients developing either under high winds under near-neutral stability or low winds. Note that the $S c K_{\mathrm{c}}$ does not approach the molecular diffusivity of the order $10^{-5} \mathrm{~m}^{2} \mathrm{~s}^{-1}$ as $\zeta$ increases to 1.0 (Fig. 6c). This was probably largely a result of the MDL for the measured $K_{\mathrm{c}}$, although it may also indicate the predominance of turbulent mixing over molecular mixing for the weak, often intermittent turbulence of the stable boundary layer. Note that the quality assurance minimized the influence of waves and other coherence structures on the calculated $S c K_{\mathrm{c}}$.

\section{2 $\mathrm{NH}_{3}$ emission fluxes from a lagoon}

It was assumed that the flux determined from the IHF method was closest to the actual flux. The $\mathrm{NH}_{3}$ flux calculated by IHF varied from near zero to $330 \mathrm{mg} \mathrm{m}^{-2} \mathrm{~h}^{-1}$ (mean $90 \mathrm{mg} \mathrm{m}^{-2} \mathrm{~h}^{-1}$ ), with 49 30-min measurements with $\varsigma$ between 0 and $0.01,139$ with $\varsigma$ between 0.01 and $0.1,86$ with $\varsigma$ between 0.1 and 1.0. A negative flux indicated flux to the lagoon from the surroundings. The IHF estimates of $\mathrm{NH}_{3}$ flux in the Indiana experiment are homogeneously spread around a relationship from logarithmic $\varsigma$.

There is an IHF positive bias due in part to the inability of the method to quantify a "plume" when the concentration field is near background values and in part to the inclusion of turbulent diffusive fluxes (Denmead, 2008). $\mathrm{NH}_{3}$ flux calculated using the three flux-gradient methods were generally lower than the IHF method (Fig. 7). This tendency was probably in part due to errors in the calculated vertical $\mathrm{NH}_{3}$ concentration gradients described previously. Since this error was present for all three flux-gradient methods, a comparison of the three methods can still give useful information concerning the ability of each method to approximate the IHF. The correlation $(r)$ between the "parameterized" fluxgradient and the IHF method was 0.53 , with root mean square error (RMSE) of $43 \mathrm{mg} \mathrm{m}^{-2} \mathrm{~h}^{-1}$ (solid line, Fig. 7). The regression for the "parameterized" flux comparison is driven by three outlying values that are not indicated in Fig. 7: the dashed line indicates the linear regressions without outliers less than zero and greater than $180 \mathrm{mg} \mathrm{m}^{-2} \mathrm{~h}^{-1}$. Removing these outliers dramatically improves the correlation between the IHF and the "parameterized" methods to $r=0.61$ with negligible change in the RMSE $\left(40 \mathrm{mg} \mathrm{m}^{-2} \mathrm{~h}^{-1}\right)$.

Calculating the flux based on the measured wind profile resulted in a better relationship to the IHF method than the "parameterized" method: $r=0.68, \mathrm{RMSE}=38 \mathrm{mg} \mathrm{m}^{-2} \mathrm{~h}^{-1}$ (Fig. 7). The use of the measured $u_{*}$ in place of the parameterized $u_{*}$ prevented the outlying flux estimates and 

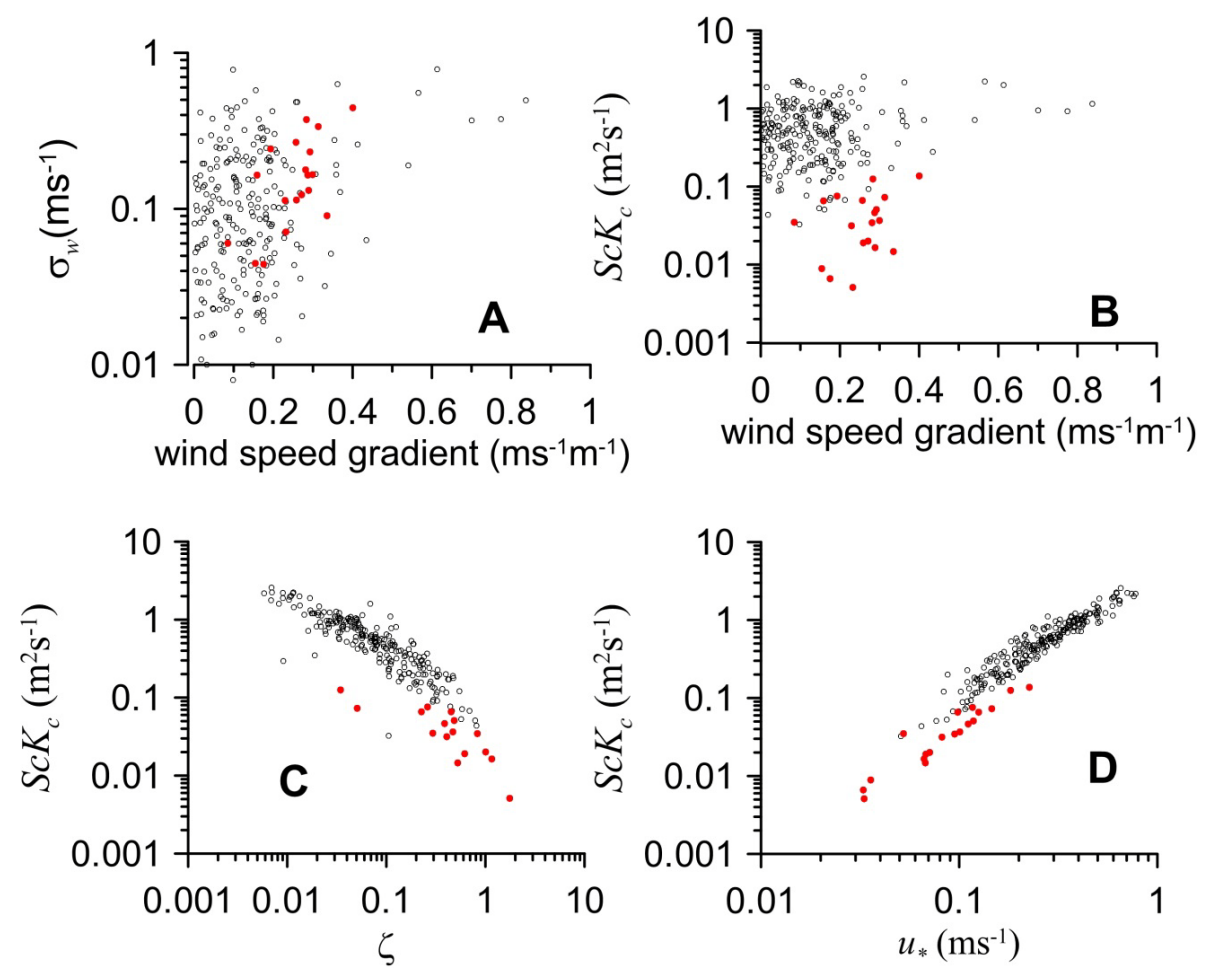

Fig. 6. Variation in vertical turbulence $\sigma_{\mathrm{w}}$ and the product of Schmidt number with turbulent diffusivity $S c K_{\mathrm{c}}$ at the flux calculation height with horizontal wind speed gradient below that height - panels (A) and (B), and variation in $S c K_{\mathrm{c}}$ with stability $\varsigma(\mathbf{C})$ and friction velocity $u_{*}(\mathbf{D})$ at that height. Values in both the Indiana (open circles) and Fuhrberg (closed red circles) experiments are indicated.
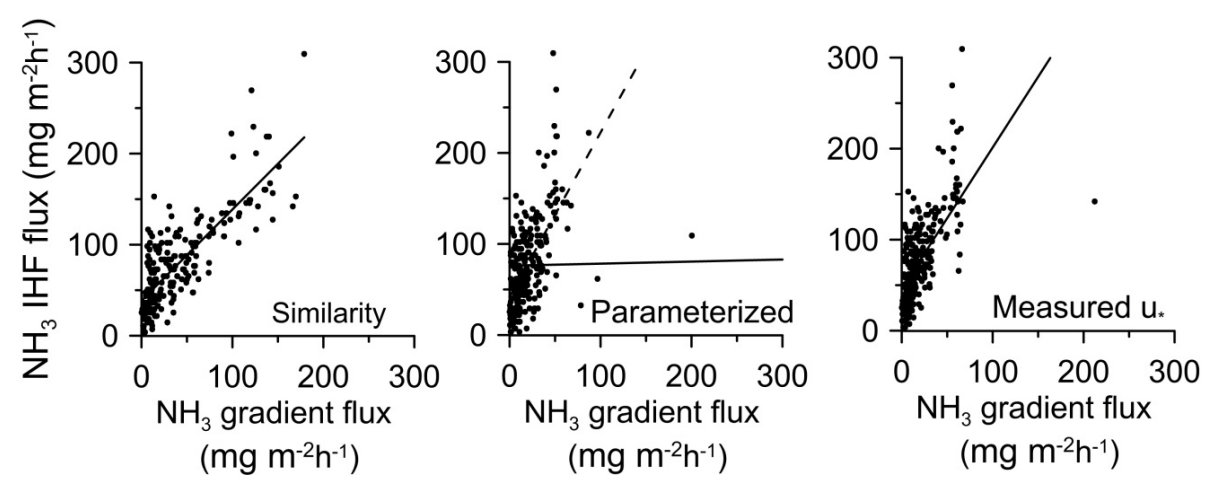

Fig. 7. The comparison between the IHF method and the flux-gradient method using $K_{\mathrm{c}}$ of "similarity" approach according to Eqs. (1) and (2), of "parameterized" approach with theoretical friction velocity $u_{*}$ and stability correction function $\psi_{\mathrm{c}}$ as well as of "measured $u_{*}$ " approach. Linear regressions between the flux measures are indicated by solid lines. The dashed line at "parameterized" flux comparison indicates the linear regressions when outliers less than zero and greater than $200 \mathrm{mg} \mathrm{m}^{-2} \mathrm{~h}^{-1}$ are neglected.

consequently is an improvement on the parameterization of $u_{*}$ (Fig. 7), with the greatest flux related to less stable conditions (Fig. 8).

The difference between the flux calculations using the parameterization of $u_{*}$ and the measurement-based $u_{*}$ suggested the wind profile was not log-linear as implied in the analysis of $\psi_{\mathrm{c}}$ (Fig. 4), reducing the utility of the parameterization to describe the gradient. This is consistent with the finding that the wind profile is commonly more linear than log-linear in the stable boundary layer (Mahrt, 2007). These non-log-linear wind profiles within the measured layer strongly influenced the flux.

The $\mathrm{NH}_{3}$ flux calculated using the "similarity" method assumed linear profiles rather than a log-linear profile of wind and concentration. This method resulted in fluxes closer to those determined by the IHF method than the other two methods that assumed log-linear profiles (Fig. 7). The correlation 


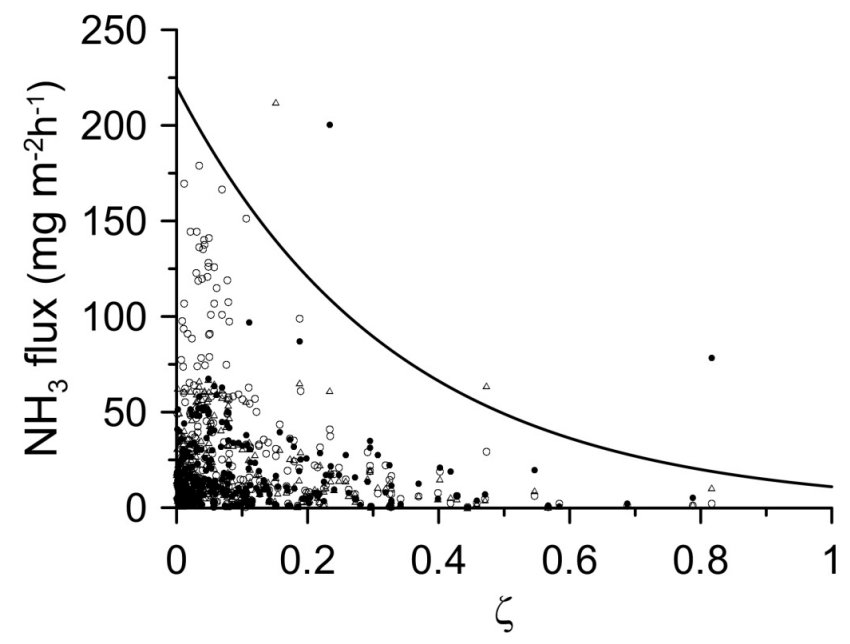

Fig. 8. The relationship between the computed fluxes and stability $\varsigma$ using flux-gradient method following a "similarity" approach (open circles), the flux-gradient method assuming a MOST parameterized stability correction function $\psi_{\mathrm{c}}$ ("parameterized" approach, closed circles), and the flux-gradient method using measured friction velocity $u_{*}$ ("measured $u_{*}$ " approach, triangles) are indicated. Three extreme outlier values of the parameterized method are not plotted. The line shows the upper emissions bound.

between the diffusivity method and the IHF method was $r=0.80$ with a RMSE of $31 \mathrm{mg} \mathrm{m}^{-2} \mathrm{~h}^{-1}$ (Fig. 7).

All flux-gradient methods resulted in estimated fluxes, with the range of values decreasing with increasing 5 (Fig. 8). This was consistent with mixing theory where mechanical turbulent mixing is suppressed by negative buoyancy to an increasing extent as the stability increases.

\section{3 $\mathrm{N}_{2} \mathrm{O}$ emission fluxes from soil}

The calculated $K_{\mathrm{c}}$ values for the Fuhrberg experiment were within the range of those calculated from the Indiana experiment and showed similar relationships to the vertical gradient in $u, u_{*}$, and $\varsigma$ (Fig. 6). The calculated diffusivity for the Fuhrberg experiment showed a decrease with the increasing stability limited by the measurement errors to values of $0.01 \mathrm{~m}^{2} \mathrm{~s}^{-1}$ (Fig. 6).

During the first campaign (16-17 October 2007), wind speeds varied from $2.3 \mathrm{~m} \mathrm{~s}^{-1}$ to $0.6 \mathrm{~m} \mathrm{~s}^{-1}$ and the surface boundary layer was characterised by stable and very stable conditions with $\varsigma$ up to 8 . This extreme stability resulted in minimal valid emissions determinations. Between 14:30 and 20:00 h of 16 October, all wind speeds (above and below) were relatively small with corresponding small wind speed gradients. During this time the difference between the concentration measurements was statistically significant (Fig. 9). Between 22:30 and 24:00 $\mathrm{h}$ the measured vertical concentration differences were statistically significant also, resulting in valid flux determinations. After this time, the difference in the two concentrations was again not statistically significant.

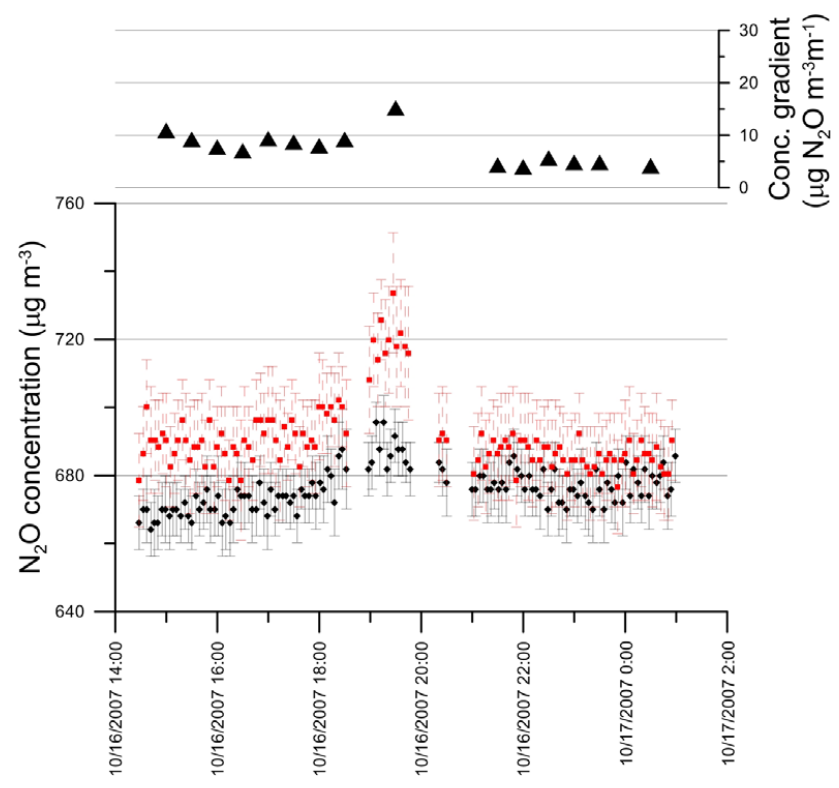

Fig. 9. Temporal variation of the $\mathrm{N}_{2} \mathrm{O}$ concentrations in ambient air (16-17 October 2007) at both heights ( $0.5 \mathrm{~m}$ : side-oriented squares, $2.7 \mathrm{~m}$ : edge-oriented squares), including the statistical errors (random absolute error as columns around the measurement value in both directions) and concentration gradients.

There are some gaps in the $\mathrm{N}_{2} \mathrm{O}$ measurement time series due to the necessity for internal optical adjustment of the spectrometers (Figs. 9 and 10).

During the second campaign, the surface boundary layer had very stable conditions and very low horizontal wind speeds with $\varsigma$ up to 11 . The $\mathrm{N}_{2} \mathrm{O}$ concentrations in ambient air (17-18 June 2008) at both heights were not significantly different (Fig. 10).

Chamber measurements of the $\mathrm{N}_{2} \mathrm{O}$ flux were made on 17 October 2007 after the first campaign when the wind speed at $2.7 \mathrm{~m}$ a.g.l. was $0.5 \mathrm{~m} \mathrm{~s}^{-1}$, the air temperature was $10^{\circ} \mathrm{C}$ and there was no precipitation. These conditions were similar to those during the flux-gradient measurements. Of the four chambers used, one had an unusually high concentration value after $40 \mathrm{~min}$ (value excluded), one failed the linearity criterion and had one unusually high concentration (flux set to 0), one indicated an up-take of $\mathrm{N}_{2} \mathrm{O}$ (linear regression $-9.2 \mu \mathrm{g} \mathrm{m}^{-2} \mathrm{~h}^{-1}$ and NDFE $\left.-13.7 \mu \mathrm{g} \mathrm{m}^{-2} \mathrm{~h}^{-1}\right)$, and one indicated flux of $155.5 \mu \mathrm{g} \mathrm{m}^{-2} \mathrm{~h}^{-1}$ by both data analysis methods. The mean of the four chamber measurements was $37 \mu \mathrm{g} \mathrm{m}^{-2} \mathrm{~h}^{-1}$ by the linear regression and $36 \mu \mathrm{g} \mathrm{m}^{-2} \mathrm{~h}^{-1}$ by the NDFE method.

The quality assurance condition of a significant difference in the concentrations for the flux-gradient method was fulfilled in only 2230 -min mean measurements of the two campaigns. Exclusions of measurement periods with high wind shear or strong waves during the averaging period resulted in valid flux-gradient measurements for only 8 of $5630-\mathrm{min}$ 


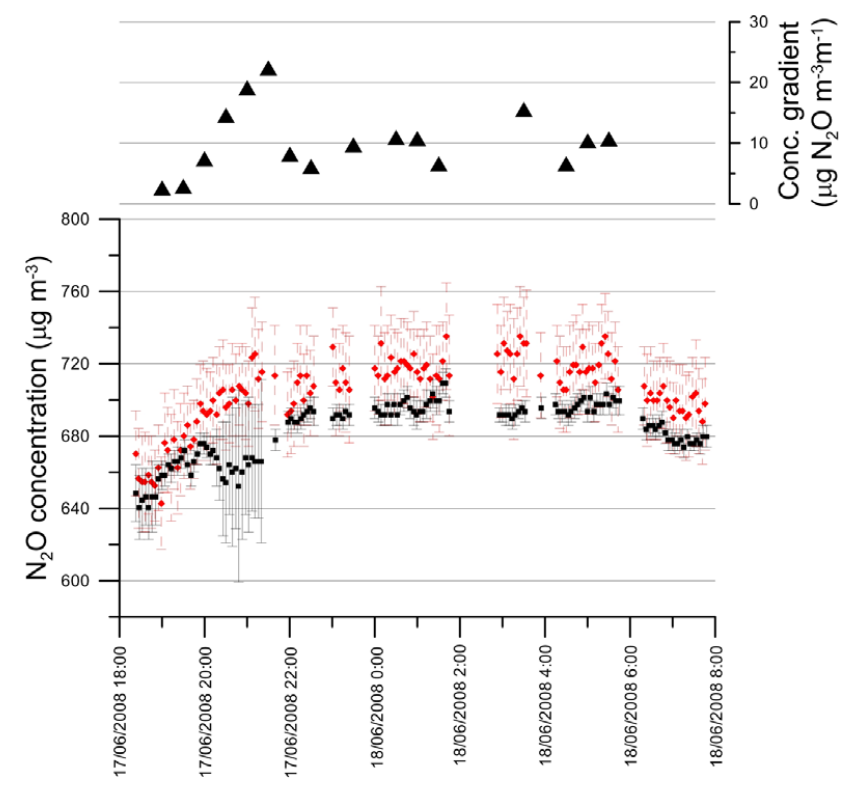

Fig. 10. Temporal variation of the $\mathrm{N}_{2} \mathrm{O}$ concentrations in ambient air (17-18 June 2008) at both heights ( $0.5 \mathrm{~m}$ : edge-oriented squares, $2.7 \mathrm{~m}$ : side-oriented squares) including the statistical errors (random absolute error as columns around the measurement value in both directions) and concentration gradients.

measurement periods. The calculated emission fluxes decrease with increasing $\varsigma$ (Fig. 11).

The $\mathrm{N}_{2} \mathrm{O}$ flux was measured by the chamber method on 19 June 2008 after the second campaign. The meteorological conditions were similar as on 17 and 18 June: no precipitation, a wind speed at $2.7 \mathrm{ma}$ a.g.l. of $0.7 \mathrm{~m} \mathrm{~s}^{-1}$, and an air temperature of $13^{\circ} \mathrm{C}$. Of the four chambers measured; one set of concentration measurements failed the linearity criteria and was assumed to be zero but was calculated as $18.4 \mu \mathrm{g} \mathrm{m}^{-2} \mathrm{~h}^{-1}$ by the NDFE method. The other chambers indicated: (1) a flux of $267.7 \mu \mathrm{g} \mathrm{m}^{-2} \mathrm{~h}^{-1}$ by both methods, (2) a flux of $97.8 \mu \mathrm{g} \mathrm{m}^{-2} \mathrm{~h}^{-1}$ by linear regression and $113.6 \mu \mathrm{g} \mathrm{m}^{-2} \mathrm{~h}^{-1}$ by NDFE method, and (3) a flux of $146.2 \mu \mathrm{g} \mathrm{m}^{-2} \mathrm{~h}^{-1}$ by linear regression and $1029.6 \mu \mathrm{g} \mathrm{m}^{-2} \mathrm{~h}^{-1}$ by NDFE. The mean measured flux was $128 \mu \mathrm{g} \mathrm{m}^{-2} \mathrm{~h}^{-1}$ using the linear regression method and $357 \mu \mathrm{g} \mathrm{m}^{-2} \mathrm{~h}^{-1}$ for the NDFE method.

The difference between the mean of the $\mathrm{N}_{2} \mathrm{O}$ emission rate results using the open-path flux-gradient methods during stable conditions averaged $236 \mu \mathrm{g} \mathrm{m}^{-2} \mathrm{~h}^{-1}$ using the "parameterized" approach, $498 \mu \mathrm{g} \mathrm{m}^{-2} \mathrm{~h}^{-1}$ using the "measured $u_{*}$ " approach and $903 \mu \mathrm{g} \mathrm{m}^{-2} \mathrm{~h}^{-1}$ using the "similarity" approach. Although similar, the average emission from the chamber measurements using the NDFE simulation was $313 \mu \mathrm{g} \mathrm{m}^{-2} \mathrm{~h}^{-1}$ (Fig. 11), which were performed at a time difference of one day in October 2007 and two days in June 2008.

The calculated $\mathrm{N}_{2} \mathrm{O}$ emission rates from the chambers and the flux-gradient methods agree with the order of magnitude

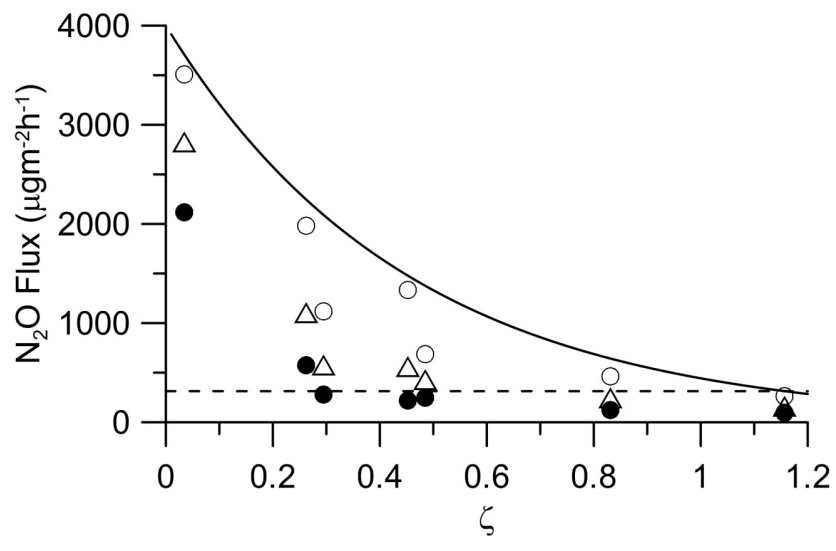

Fig. 11. Dependence of the calculated fluxes on the stability $\varsigma$ of the boundary layer $(\varsigma>0)$. The flux measurement based on the "similarity" approach (open circles), MOST parameterized flux-gradient theory ("parameterized" approach, closed circles), and measured friction velocity $u_{*}$ flux-gradient theory ("measured $u_{*}$ " approach, open triangles) is indicated. The dashed line indicates the chambermeasured flux (see text). The line shows the upper emissions bound.

of chamber and box flux measurements from other grasslands. Dittert et al. (2005) found $\mathrm{N}_{2} \mathrm{O}$ fluxes of 2 to $19 \mu \mathrm{g} \mathrm{m}^{-2} \mathrm{~h}^{-1}$ over similar soils in Northern Germany grassland. Goossens et al. (2001) determined $\mathrm{N}_{2} \mathrm{O}$ fluxes from 10 to $2200 \mu \mathrm{g} \mathrm{m}^{-2} \mathrm{~h}^{-1}$ from Belgian grassland.

\section{Data interpretation and discussion}

Assuming the IHF method provided the most accurate flux estimate, the fluxes calculated in the Indiana experiment using the "similarity" method that correlated better with the IHF method than the MOST flux-gradient methods were the most accurate of the flux-gradient methods considered. Since the MOST flux-gradient methods were based on the "measured $u_{*}$ " or "parameterized" approach, it appears that the MOST flux-gradient methods incorrectly assumed log-linear profile of the wind speed and concentration gradient in the stable boundary layer. Consequently it was assumed that the "similarity" method provided the best estimate of $\mathrm{N}_{2} \mathrm{O}$ flux in the Fuhrberg experiment also.

The similarity-based $\mathrm{N}_{2} \mathrm{O}$ fluxes at Fuhrberg exhibited similar variability with respect to stability as the Indiana experiment, and were comparable to the mean $\mathrm{N}_{2} \mathrm{O}$ flux measurements made at Fuhrberg by other methods as well as reported in the literature.

The "similarity" method resulted in the highest fluxes of all the flux-gradient methods considered for both the Indiana and Fuhrberg experiments (Figs. 8 and 11). The flux based on a measured $u_{*}$ was similar but generally greater than that based on the MOST parameterization in both the Indiana and Fuhrberg experiments. All three approaches to calculate the flux using flux-gradient methods showed similar tendencies. 
As with the upper emissions bound of the Indiana experiment (Fig. 8), the emission rates during near-neutral conditions were much higher than during stable conditions (Fig. 11). This was likely caused by changes in weather conditions such as higher wind speeds with correlated greater mixing, causing enhanced emission processes of the soil or by higher soil and lagoon temperatures which will change equilibrium gas concentrations. However it is important to remember that near-neutral conditions do not necessarily result in higher emissions, as evidenced by the results for the $\mathrm{NH}_{3}$ emissions in Indiana (Fig. 8). The negative exponential tendency affects only the maximum possible flux, as a smaller concentration gradient would reduce the flux under near neutral conditions. The range of possible flux values across the range of stability $\varsigma$ was evident in the $\mathrm{NH}_{3}$ fluxes in Indiana (Fig. 8).

The prerequisites for the application of a flux-gradient measurement method include: (1) negligible advection; (2) negligible chemical changes during the transport of air from the footprint to the measurement system; and (3) vertical turbulent exchange in a not too stable, neutral or slightly unstable lower atmosphere $(s \leq 10)$. The Fuhrberg field had good visually-determined horizontal homogeneity and the measurement periods reported here showed verticallyconsistent turbulence regardless of wind direction (see Foken, 2008, p. 26, and Schmid, 1994). The horizontal homogeneity at the Indiana location was only generally fulfilled due to the close proximity of the lagoon source to the measurement planes. This resulted in variable surface roughness and stability associated with wind direction due to the lagoon apparently influencing the universal wind profile (and the stability influence on the profile) and possibly decreasing the correlations between the IHF and flux-gradient calculation methods. The condition of turbulent linkage between the surface and the height of measurements was verified for the stable conditions studied by restricting analysis to periods with low vertical wind shear, velocity gradient (Indiana experiment only), stability, and consistency of turbulent structure even if those periods are intermittently occurring within the turbulence time history.

\section{Conclusions}

The use of open-path flux-gradient methods in non-intrusive up-scaling of trace gas fluxes near the surface was demonstrated here for $\mathrm{N}_{2} \mathrm{O}$ and $\mathrm{NH}_{3}$ in stable boundary layers and path lengths of $100 \mathrm{~m}$. A "similarity" approach that does not assume log-linear relationship of wind speed and concentration with height is the best method to approximate the flux under stable conditions $(0<\varsigma<1)$. The determination of flux under these stable conditions however requires careful evaluation of the continuity of turbulence between the surface and the height of measurement for this approach also.

\subsection{Advantages and disadvantages of the open-path flux-gradient methods}

In general the application of flux-gradient methods for trace gas flux determinations is difficult to use when either there are: (1) low wind speeds with poorly defined wind speed gradients and typically high vertical concentration gradients or (2) high wind speeds with small concentration gradients. Under stable conditions the weak and intermittent turbulence further restricts the use of micro-meteorological measurement of fluxes to conditions in which this turbulence is consistent across the layer and where the variability in vertical motion is not a result of waves or other structures that do not transfer mass vertically in the boundary layer. Of the fluxgradient methods considered, the approach using the "similarity" flux-gradient method resulted in the smallest difference to the IHF flux calculation, implying that the wind gradient and/or concentration gradient is not log-linear under stabile conditions and therefore MOST cannot be applied.

\subsection{Limitations to large-scale long-term emissions determination}

Careful quality assurance of sonic anemometers provided sufficient accuracy, precision, and detection limits for flux determination and qualification in the stable boundary layer using a flux-gradient method. A primary limitation on the yield of valid flux measurements from these methods was instrument sensitivity; the precision of the sonic anemometers was sufficient to define the vertical gradient in wind speeds and turbulence parameters but the available FTIR spectrometer for the $\mathrm{N}_{2} \mathrm{O}$ measurements did not routinely provide the necessary precision and detection limits to determine a statistically significant concentration gradient needed for flux determination. The use of a wider range in height may improve the flux estimate provided the lower measurement can be made closer to the surface. The FTIR also required internal optical adjustments which were dependent on the temperature environment and these adjustments significantly interrupted the measurement series. This was a first attempt at using flux-gradient methods in stable boundary layers with local perturbation partially averaged out by using open-path gas concentration measurements. A more sophisticated, longer term demonstration of the performance of trace gas flux determination by open-path gas measurements and flux-gradient approaches is needed to confirm applicability, ideally with spatially averaged turbulence measures matching the optical path of the gas measurement. 
Acknowledgements. We like to thank the German Science Foundation (grant SCHA 571/6-1 and -3), the Helmholtz Association, and dairy producers in conjunction with the Agricultural Air Research Council, Inc. for funding this work. The assistance of Carsten Jahn, Michael Wiwiorra, Nils-Demian Landmeyer, Christoph Bonecke, and Joris Fahle of the IMK-IFU, Jürgen Böttcher and Marcus Deurer of the Institute of Soil Science of the University of Hannover, Anja Schleichardt and Manuela Barth of the Institute for Meteorology of the University of Leipzig, Heinz Flessa, Reinhard Well, and Daniel Weymann of the Büsgen Institute of the University of Göttingen, Helmut Geistlinger and Danny Eisermann of the Helmholtz Center for Environmental Research UFZ LeipzigHalle, Wilhelmus Duijnisveld and Gunther Klump of the Federal Institute for Geosciences and Natural Resources Hannover, Stefan Neser from the Bavarian State Research Center for Agriculture Freising, and Matthew Boehm, Alfred Lawrence, Jenafer Wolf, Scott Cortus, and Derrick Snyder of Purdue University West Lafayette is much appreciated. We also thank Klaus ButterbachBahl, Hans Papen, Peter Werle, and Peter Suppan of the IMK-IFU and Thomas Foken from the University of Bayreuth for valuable discussions. We also thank the two anonymous reviewers for their very valuable comments.

The service charges for this open access publication have been covered by a Research Centre of the Helmholtz Association.

Edited by: D. Feist

\section{References}

Andreas, E. L.: Obtaining surface momentum and sensible heat fluxes from crosswind scintillometers, J. Atmos. Ocean. Tech., 17, 3-15, 2000.

Barth, M., Raabe, A., Arnold, K., Resagk, C., and du Puits, R.: Flow field detection using acoustic travel time tomography, Meteorol. Z., 16, 443-450, 2007.

Businger, J. A., Wyngaard, J. C., Isumi, Y., and Bradley, E. F.: Fluxprofile relationship in the atmospheric surface layer, J. Atmos. Sci., 28, 181-189, 1971.

Butterbach-Bahl, K., Koch, M., Willibald, G., Hewett, B., Buhagiar, S., Papen, H., and Kiese, R.: Temporal variations of fluxes of $\mathrm{NO}, \mathrm{NO}_{2}, \mathrm{~N}_{2} \mathrm{O}, \mathrm{CO}_{2}$ and $\mathrm{CH}_{4}$ in a tropical rain forest ecosystem, Global Biogeochem. Cy., 18, GB3012, doi:10.1029/2004GB002243, 2004.

Chapuis-Lardy, L., Wrage, N., Metay, A., Chotte, J.-L., and Bernoux, M.: Soils, a sink for $\mathrm{N}_{2} \mathrm{O}$ ? A review, Global Change Biol., 13, 1-17, 2007.

Denman, K. L., Brasseur, G., Chidthaisong, G. Ciais, P. M., Cox, R. E., Dickinson, D., Hauglustaine, C., Heinze, E., Holland, E., Jacob, D., Lohmann, U., Ramachandran, S., da Silva, D., Wofsy, F. C., and Zhang, X.: Couplings between changes in the climate system and biogeochemistry, in: Climate Change 2007: The Physical Science Basis, Contributing of Working Group 1 to the Fourth Assessment Report of the Intergovernmental Panel on Climate Change, edited by: Solomon, S., Quin, M., Manning, M., Chen, Z., Marquis, M., Averyt, K. B., Tigor, M., and Miller, H. L., Cambridge University Press, Cambridge, UK and New York, NY, USA, 499-587, 2007.
Denmead, O. T.: Approaches to measuring fluxes of methane and nitrous oxide between landscapes and the atmosphere, Plant Soil, 309, 5-24, 2008.

Deurer, M., von der Heide, C., Böttcher, J., Duijnisveld, W. H. M., Weymann, D., and Well, R.: The dynamics of $\mathrm{N}_{2} \mathrm{O}$ near the groundwater table and the transfer of $\mathrm{N}_{2} \mathrm{O}$ into the unsaturated zone: A case study from a sandy aquifer in Germany, Catena, 72, 362-373, 2008.

Dittert, K., Lampe, C., Gasche, R., Butterbach-Bahl, K., Wachendorf, M., Papen, H., Sattelmacher, B., and Taube, F.: Short-term effects of single or combined application of mineral $\mathrm{N}$ fertilizer and cattle slurry on the fluxes of radiatively active trace gases from grassland soil, Soil Biol. Biochem., 37, 1665-1674, 2005.

Dyer, A. J.: A review of flux-profile relationships, Bound.-Lay. Meteorol., 7, 363-372, 1974.

Esler, M. B., Griffith, D. W. T., Turatti, F., Wilson, S. R., Rahn, T., and Zhang, H.: $\mathrm{N}_{2} \mathrm{O}$ concentration and flux measurements and complete isotopic analysis by FTIR spectroscopy, Chemosphere - Global Change Sci., 2, 445-454, 2000.

Fernando, H. J. S. and Weil, J. C.: Whither the stable boundary layer. A shift in the research agenda, B. Am. Meteorol. Soc., 91, 1475-1485, 2010.

Foken, T.: Micrometeorology, ISBN: 978-3-540-74665-2, Springer, Berlin, Heidelberg, New York, 308 pp., 2008.

Forster, P., Ramaswamy, V., Artaxo, P., Berntsen, T., Betts, R., Fahey, D. W., Haywood, J., Lean, J., Lowe, D. C., Myhre, G., Nganga, J., Prinn, R., Raga, G., Schulz, M., and van Dorland, R.: Changes in Atmospheric Constituents and in Radiative Forcing, in: Climate Change 2007: The Physical Science Basis, Contributions of Working Group I to the Fourth Assessment Report of the Intergovernmental Panel on Climate Change, edited by: Solomon, S., Qin, D., Manning, M., Chen, Z., Marquis, M., Averyt, K. B., Tignor, M., and Miller, H. L., Cambridge University Press, Cambridge, UK and New York, NY, USA, 2007.

Galle, B., Klemedtsson, L., and Griffith, D. W. T.: Application of a Fourier transform IR system for measurement of $\mathrm{N}_{2} \mathrm{O}$ fluxes using micrometeorological methods, an ultralarge chamber system and conventional chambers, J. Geophys. Res., 99, 16575-16583, 1994.

Goossens, A., De Visscher, A., and Boeckx, P.: Two-year field study on the emission of $\mathrm{N}_{2} \mathrm{O}$ from coarse and middle-textured Belgian soils with different land use, Nutr. Cycl. Agroecosys., 60, 23-34, 2001.

Griffith, D. W. T.: FT-IR Measurements of Atmospheric Trace Gases and their Fluxes, in: Handbook of Vibrational Spectroscopy, edited by: Chalmers, J. M. and Griffiths , P. R., John Wiley \& Sons Ltd, Chichester, UK, 1-19, 2002.

Griffith, D. W. T., Leuning, R., Denmead, O. T., and Jamie, I. M.: Air-land exchanges of $\mathrm{CO}_{2}, \mathrm{CH}_{4}$ and $\mathrm{N}_{2} \mathrm{O}$ measured by FTIR spectrometry and micrometeorological techniques, Atmos. Environ., 36, 1833-1842, 2002.

Hashmonay, R. A., Natschke, D. F., Wagoner, K., Harris, D. B., Thompson, E. L., and Yost, M. G.: Field Evaluation of a Method for Estimating Gaseous Fluxes from Area Sources Using OpenPath Fourier Transform Infrared, Environ. Sci. Technol., 35, 2309-2313, 2001.

Haus, R., Schäfer, K., Bautzer, W., Heland, J., Mosebach, H., Bittner, H., and Eisenmann, T.: Mobile FTIS-Monitoring of Air Pollution, Appl. Optics, 33, 5682-5689, 1994. 
Hicks, B. B.: Wind profile relationships from the Wangara experiments, Q. J. Roy. Meteorol. Soc., 102, 535-551, 1976.

Holtslag, A. A. M. and de Bruin, H. A. R.: Applied Modeling of the Nighttime Surface Energy Balance over Land, J. Appl. Meteorol., 27, 689-704, 1988.

Lege, D.: Eine Betrachtung der Bestimmung des Stroms fühlbarer Wärme und der Schubspannungsgeschwindigkeit aus Temperatur- und Windgeschwindigkeitsdifferenzen, Meteorol. Rundsch., 34, 1-4, 1981.

Livingston, G. P., Hutchinson, G. L., and Spartalian, K.: Trace gas emission in chambers: a non-steady-state diffusion model, Soil Sci. Soc. Am. J., 70, 1459-1469, 2006.

Luhar, A. K., Hurley, P. J., and Raynor, K. N.: Modelling nearsurface low winds over land under stable conditions: sensitivity tests, flux-gradient relationships, and stability parameters, Bound.-Lay. Meteorol., 130, 249-274, 2009.

Mahrt, L.: The influence of nonstationarity on the turbulent fluxgradient relationship for stable stratification, Bound.-Lay. Meteorol., 125, 245-264, 2007.

Mahrt, L.: Variability and maintenance of turbulence in the very stable boundary layer, Bound.-Lay. Meteorol., 135, 1-18, 2010.

Massman, W. J.: A review of the molecular diffusivities of $\mathrm{H}_{2} \mathrm{O}$, $\mathrm{CO}_{2}, \mathrm{CH}_{4}, \mathrm{CO}, \mathrm{O}_{3}, \mathrm{SO}_{2}, \mathrm{NH}_{3}, \mathrm{~N}_{2} \mathrm{O}, \mathrm{NO}$, and $\mathrm{NO}_{2}$ in air, $\mathrm{O}_{2}$ and $\mathrm{N}_{2}$ near STP, Atmos. Environ., 32, 111-127, 1998.

Nakaya, K., Suzuki, C., Kobayashi, T., Ikeda, H., and Yasuike, S.: Spatial averaging effect on local flux measurement using a displaced-beam small aperture scintillometer above the forest canopy, Agr. Forest Meteorol., 145, 97-109, 2007.

Schäfer, K., Böttcher, J., Weymann, D., Von der Heide, C., Duijnisveld, W.: Evaluation of a closed tunnel for field-scale measurements of $\mathrm{N}_{2} \mathrm{O}$ fluxes at the soil-atmosphere interface, J. Environ. Qual., doi:10.2135/jeq2011.0475, in press, 2012.

Schmid, H. P.: Source areas for scalars and scalar fluxes, Bound.Lay. Meteorol., 67, 293-318, 1994.

Smith, K. A., Clayton, H., Arah, J. R. M., Christensen, S., Ambus, P., Fowler, D., Hargreaves, K. J., Skiba, U., and Harris, G. W.: Micrometeorological and chamber methods for measurement of nitrous oxide fluxes between soils and the atmosphere: overview and conclusions, J. Geophys. Res., 99, 16541-16548, 1994.
Stull, R. B.: An Introduction to Boundary Layer Meteorology, Kluwer Academic Publishers, The Netherlands, 666 pp., 1997.

Sussmann, R. and Schäfer, K.: Infrared spectroscopy of tropospheric trace gases: combined analysis of horizontal and vertical column abundances, Appl. Optics, 36, 735-741, 1997.

Taylor, J. R.: An introduction to error analysis: the study of uncertainties in physical measurements, University Science Books, Mill Valley, CA, 270 pp., 1982.

Turner, D. A., Chen, D., Galbally, I. E., Leuning, R., Edis, R. B., Li, Y., Kelly, K., and Phillips, F.: Spatial variability of nitrous oxide emissions from an Australian irrigated dairy pasture, Plant Soil, 309, 77-88, 2008.

von der Heide, C., Böttcher, J., Deurer, M., Duijnisveld, W. H. M., Weymann, D., and Well, R.: Estimation of indirect $\mathrm{N}_{2} \mathrm{O}$ emissions from a shallow aquifer in northern Germany, J. Environ. Qual., 38, 2161-2171, doi:10.2134/jeq2008.0320, 2009.

Weymann, D., Well, R., von der Heide, C., Böttcher, J., Flessa, H., and Duijnisveld, W. H. M.: Recovery of groundwater $\mathrm{N}_{2} \mathrm{O}$ at the soil surface and its contribution to total $\mathrm{N}_{2} \mathrm{O}$ emissions, Nutr. Cycl. Agroecosys., 85, 299-312, doi:10.1007/s10705-009-92694, 2009

Wichink Kruit, R. J., Van Pul, W. A. J., Otjes, R. P., Hofschreuder, P., Jacobs, A. F. G., and Holtslag, A. A. M.: Ammonia fluxes and derived canopy compensation points over non-fertilized agricultural grassland in the Netherlands using the new gradient ammonia-high accuracy-monitor (GRAHAM), Atmos. Environ., 41, 1275-1287, 2007.

Wichink Kruit, R. J., Volten, H., Haaima, M., Swart, D. P. J., van Zanten, M. C., and van Pul, W. A. J.: Ammonia exchange measurements over a corn field in Lelystad, the Netherlands in 2009, RIVM Report 680180002/2010, Bilthoven, The Netherlands, 61 pp., 2010. 